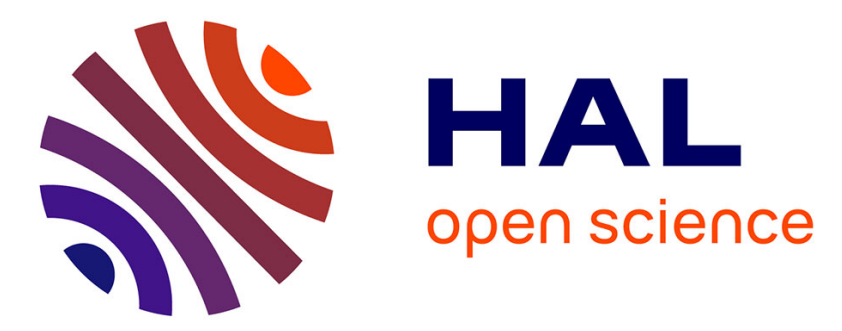

\title{
Modeling the visco-hyperelastic--viscoplastic behavior of photodegraded semi-crystalline low-density polyethylene films
}

\author{
Georges Ayoub, A.K. Rodriguez, B. Mansoor, Xavier Colin
}

\section{- To cite this version:}

Georges Ayoub, A.K. Rodriguez, B. Mansoor, Xavier Colin. Modeling the visco-hyperelasticviscoplastic behavior of photodegraded semi-crystalline low-density polyethylene films. International Journal of Solids and Structures, 2020, 204-205, pp.187-198. 10.1016/j.ijsolstr.2020.08.025 . hal02943943

\section{HAL Id: hal-02943943 \\ https://hal.science/hal-02943943}

Submitted on 21 Sep 2020

HAL is a multi-disciplinary open access archive for the deposit and dissemination of scientific research documents, whether they are published or not. The documents may come from teaching and research institutions in France or abroad, or from public or private research centers.
L'archive ouverte pluridisciplinaire HAL, est destinée au dépôt et à la diffusion de documents scientifiques de niveau recherche, publiés ou non, émanant des établissements d'enseignement et de recherche français ou étrangers, des laboratoires publics ou privés. 


\title{
Modeling the visco-hyperelastic-viscoplastic behavior of photodegraded semi-crystalline low-density polyethylene films
}

\author{
G. Ayoub ${ }^{\mathrm{a}, *}$, A.K. Rodriguez ${ }^{\mathrm{b}, \mathrm{c}}$, B. Mansoor ${ }^{\mathrm{b}, \mathrm{c}}, \mathrm{X}$. Colin $^{\mathrm{d}}$ \\ a Department of Industrial and Manufacturing Systems Engineering, University of Michigan-Dearborn, Dearborn, MI 48128, USA \\ ${ }^{\mathrm{b}}$ Department of Materials Science E' Engineering, Texas AE'M University, College Station, TX 77843, USA \\ ${ }^{\mathrm{c}}$ Department of Mechanical Engineering, Texas A\&M University at Qatar, Doha 28874, Qatar \\ d PIMM, Arts et Métiers Institute of Technology, 151 boulevard de l'Hôpital, 75013 Paris, France
}

\section{Keywords:}

Polymeric material

Photo-degradation

Visco-hyperelastic-viscoplastic modeling

Chain scissions

Chemi-crystallization

\begin{abstract}
A B S T R A C T
In this work we propose to model the mechanical and fracture response of semi-crystalline low-density polyethylene (LDPE) films exposed to accelerated ultraviolet (UV) ageing using a physically based viscohyperelastic-viscoplastic approach. UV irradiation induces an alteration of the chemical and structural properties of the semi-crystalline polymer, which affects significantly its mechanical behavior. In this work, pristine and oxidized low-density polyethylene films are characterized by conventional physicochemical and mechanical techniques (FTIR spectroscopy, DSC, HT-GPC, and uniaxial tensile testing). Polyethylene exhibits an oxidation-induced strengthening for a low range of UV radiation doses and a cavitation-induced softening for higher UV radiation doses. A competing multi-scale phenomena induced by UV radiation are incorporated into the constitutive model to capture the macroscopically observed mechanical and fracture behavior. Namely, the model will incorporate at the nano scale, chain scissions and cross-linking and at the meso and macro scales, oxidation-induced cracking, chemi-crystallization, and mechanical damage. The model used the high-temperature gel permeation chromatographymeasured molecular weight as degradation indicator. The model was able to capture accurately the evolution of the macroscopically observed mechanical and fracture behavior over a wide range of UV irradiation doses.
\end{abstract}

\section{Introduction}

Semi-crystalline polymers are used as structural applications subjected to extreme environmental conditions, such as solar cells, pipelines, and greenhouses and in the automotive and aerospace industries. Therefore, the polymers' sustainability and resistance to environmental conditions, such as heat, UV radiation, and humidity, determine their useful life and their economic and environmental impact. UV radiation of polymers is found to induce oxidation and mechanical degradation. UV degradation can lead to chain scissions and/or to crosslinking, altering the mechanical and aesthetic properties that usually define the usability of a polymer product. Consequently, UV degradation leads to significant loss in the materials' ductility (Briassoulis et al., 2004; Carrasco et al., 2001; Chabira et al., 2006; Fayolle et al., 2008, 2007; Hsu et al., 2012; Liu et al., 1995; Miyagawa et al., 2007; Sebaa et al.,

\footnotetext{
* Corresponding author.

E-mail address: gayoub@umich.edu (G. Ayoub).
}

1993; Rodriguez et al., 2020) as well as to significant discoloration or yellowing (Rabek, 1995).

In the presence of oxygen and light, polymers can undergo photo-oxidation. In addition to hydroperoxide decomposition, photo-oxidation of polyolefins can be initiated by two other types of reactions involving ketone groups: Norrish type I and Norrish type II (Gardette et al., 2013; Grigoriadou et al., 2011; Rabek, 1995). These three initiation reactions lead primarily to chain scissions and secondarily to crosslinking, but Norrish type II also results into the formation of unsaturations. The sensitivity of polyolefins to photo-oxidation depends on their chemical formulation (antioxidants, reactive fillers, etc.), but also on their physical properties such as molecular weight, crystallinity, and orientation of macromolecular chains. Chain scissions induce a clear reduction in the average molecular weight and a narrowing of the polydispersity (the distribution of molecular weight) (Hsu et al., 2012; Rolón-Garrido et al., 2015). Fayolle et al. (2008), Fayolle et al. (2007) related the embrittlement of semi-crystalline polyethylene to the reduction in the molecular weight and identified a severe ductile-to-brittle transition for a critical interlamellar thickness, 
$l_{a c}=6 \mu \mathrm{m}$, or a critical average molecular weight, $M_{w c}=70 \mathrm{~kg} / \mathrm{mol}$ ( $M_{w c}$ is different for each polymer). It is generally assumed that the photo-oxidation reactions in semi-crystalline polymers occur in the amorphous region favorable to oxygen diffusion relative to dense crystallites. The amorphous region, which is "trapped" between crystalline domains, is where chain scissions and crosslinking would occur. Additionally, a type of (lowtemperature) secondary crystallization, referred to as chemicrystallization, can be induced by chain scissions (Craig and White, 2005). These macromolecular (crystallinity and average molecular weight of polymers) changes are assumed to be directly responsible for the alteration of the mechanical response of the polymers. Strain at break is one of the most widely studied mechanical properties in photo-oxidation. Strain at break tends to decrease as the degradation proceeds (Briassoulis et al., 2004; Carrasco et al., 2001; Chabira et al., 2006; Fayolle et al., 2008, 2007; Hsu et al., 2012; Liu et al., 1995; Miyagawa et al., 2007; Sebaa et al., 1993), while the stiffness and hardness of polyethylene was found to increase with UV degradation (Carrasco et al., 2001; Chabira et al., 2006; Gulmine et al., 2003; Tavares et al., 2003). These last changes have been attributed to chemi-crystallization and/or crosslinking reactions.

It is appropriate to consider semi-crystalline polymers as heterogeneous materials consisting of two solid phases: A crystalline phase, and an amorphous phase. The mechanical behavior of semicrystalline thermoplastics depends on microstructural factors such as the length of the macromolecular chains, entanglement between chains, cross-linking, crystalline phase volume fraction, size, shape and orientation of the crystalline lamellas (Ayoub et al., 2011). For example, the crystallinity ratio and the organization hierarchy that impact the mechanical properties of polyethylene (PE) are influenced by a particularly large variety of molecular architectures (Peacock, 2000). The mechanical behavior of semi-crystalline PE is time dependent and can exhibit quasielastomeric behavior at low crystal content and evolve to show a typical thermoplastic behavior at high crystal content (Ayoub et al., 2011). Under cyclic loading semicrystalline PE exhibit a dissipative behavior characterized by the presence of hysteresis loops accompanied with mechanical properties deterioration (Lin and Argon, 1994; Makki et al., 2017; Qi et al., 2019). With increasing temperature, it is reported that the mechanical response of semicrystalline thermoplastic such as yield stress, initial Young's modulus and strain hardening decrease while ductility increase (Brooks et al., 1998). While under cyclic loading condition at constant maximum strain a decrease of the maximum stress and of the residual strain is reported with increasing temperature (Drozdov, 2010). On the other hand, an increase of the yield stress, plastic flow and the strain hardening and a decrease of the ductility with increasing strain rate is reported (Ayoub et al., 2011; Richeton et al., 2006). Additionally, semicrystalline polymers present a highly anisotropic response depending on the loading direction and loading path (Hachour et al., 2014).

Over the past two decades, the elastic-viscoplastic deformation behavior of semi-crystalline polymers has been modeled using either phenomenological or physical-based approaches. Many investigations used phenomenological mathematical framework to describe the mechanical behavior of semi crystalline thermoplastics (Balieu et al., 2013; Bardenhagen et al., 1997; Hamouda et al., 2007; Cayzac et al., 2013; Colak, 2005; Drozdov, 2009, 2010; Drozdov and Gupta, 2003; Dusunceli and Colak, 2008, 2006; Ghorbel, 2008; Haward and Thackray, 1968; Khan and Zhang, 2001; Krempl and Khan, 2003; Regrain et al., 2009a, 2009b; Zaïri et al., 2005a, 2005b, 2008; Zhang and Moore, 1997; Billon, 2012; Maurel-Pantel et al., 2015; Gehring et al., 2016; Nguyen et al., 2016; Huang et al., 2011; Khan and Yeakle, 2011; Qi et al., 2019; Selles et al., 2016; Drozdov et al., 2013, 2007;
Krairi and Doghri, 2014))). In the physical-based approaches the macro mechanical behavior of thermoplastics is captured by the development of constitutive modeling based on the motion of molecular chains. In these models the deformation of the macromolecular network is physically related to the chains chemical properties ((Boyce et al., 1988; Arruda et al., 1995; Wu and van der Giessen, 1996; Adams et al., 2000; Ahzi et al., 2003; Anand and Ames, 2006; Anand and Gurtin, 2003; Arruda et al., 1995; Boyce et al., 1989a, 1989b; Buckley and Jones, 1995; Detrez et al., 2010; Hachour et al., 2014; Makradi et al., 2005; Wu and van der Giessen, 1995; Zaïri et al., 2011; Garcia-Gonzalez et al., 2017). Haward and Thackray (1968) inspired most of the modeling efforts devoted to capturing the behavior of amorphous and semicrystalline polymers. In the next paragraph, a summary of the recent developments for describing the large deformation behavior of semi-crystalline polymers is provided. van Dommelen et al. (2003) represented the semi-crystalline polymer as a randomly oriented aggregate of two-phase layered composite inclusions and captured the elasto-viscoplastic behavior by modifying the micromechanical model of Lee (1993). Alternatively, a microstructure-based composite-type formulation was used and extended by several investigations for modeling the behavior of semi-crystalline thermoplastics. Rheological models for semicrystalline thermoplastics were suggested first by Boyce et al. (2000) and described the deformation mechanisms by a network resistance, describing the deformation of sliding and stretching of the polymer chains, acting in parallel with an intermolecular resistance, capturing the plasticity. Later, Ahzi et al. (2003) and Makradi et al. (2005) considered the intermolecular resistance to be a combination of amorphous and crystalline phases. Ayoub et al. (2011), Ayoub et al. (2010) and Makki et al. (2017) improved the modeling capabilities of the approach under olygocyclic loading (strain controlled cyclic loading) by directly incorporating the nonlinear viscosity effects on the elastic part. In both cases, the Arruda and Boyce (1993) eight-chain model was used to describe the stress developed by the network.

In the last decade, a few studies have attempted to model the effect of environmental degradation on the mechanical properties of polymers. Belbachir et al. (2010) incorporated the effect of UV aging into a physical-based elastic-viscoplastic model to capture the degradation in the mechanical behavior of PLA. To that end, a photo-degradation parameter based on the change in the molecular weight of PLA was used as a direct input into the model. Soares et al. (2010), Soares et al. (2008) studied the deformation-induced degradation of a biodegradable polymer. The evolution in the mechanical properties was modeled using a hyperelastic, neoHookean model coupled with a scalar field that captures the local state of degradation. The hydrolytic degradation of biodegradable polymers was studied by Vieira et al. (2014), Vieira et al. (2011) and Breche et al. (2016a), Breche et al. (2016b). They both proposed physically based models to predict the effect of hydrolytic degradation on the mechanical behavior. Viera et al. integrated the hydrolytic degradation kinetics into the Bergström and Boyce (1998) model to predict the behavior of PLA-PCL blends. Breche et al. integrated a degradation scalar parameter, calibrated on normalized relaxation curves, into an adaptive quasi-linear viscoelastic model to predict the mechanical behavior of a PLA-b-PEG-b-PLA triblock copolymer during hydrolytic degradation. Wang et al. (2010) proposed a model that relates the molecular weight of an amorphous biodegradable polymer with the elastic modulus based on Ward and Hadley's entropy spring model (Ward and Sweeney, 2005). The model coupled the elastic spring theory model with the phenomenologically based diffusion reaction biodegradation model proposed by Wang et al. (2008) and Han and Pan (2009) that describes the relationship between monomer diffusion and the hydrolysis process. Those studies focused solely on the Young's 
modulus evolution. Recently, Zhao et al. (2016) and Zhao and Zikry (2017) used an elasto-plastic formulation to predict the mechanical response of semi-crystalline poly(3-hexylthiophene-2,5-diyl)( P3Ht) thin film. A stress-coupling term based on a modified Fick's second law for stress-assisted diffusion reactions was proposed to capture the effect of oxidation on the mechanical behavior. Johlitz et al. (2014) investigated the thermo-oxidative ageing of elastomers and proposed a phenomenological model by modifying the Clausius-Planck inequality and introducing an additive decomposition of Helmholtz free energy to account for the thermal degradation. Sinilarly, Nait Abdelaziz et al. (2019) investigated the effect of thermal aging and compared two approaches for predicting evolution of the mechanical properties of elastomers. The first approach is based on the stress limiter approach while the second one is an extension of the energy limiter approach. Under mechanical loading, the energy limiter approach limits the stored energy in the rubber. Actually, the classical hyperelastic constitutive laws do not capture the material fracture inducing stress drop. Adding the energy limiter to the constitutive equations allows describing the entire curve, including the stress drop. The main features of this approach are summarized in Volokh, 2016, Volokh, 2017, Volokh, 2010, Volokh, 2007.

The present work aims at modeling the visco-hyperelastic-vis coplastic and fracture behavior of UV aged semi-crystalline lowdensity polyethylene (LDPE) films behavior. Relying on our understanding of the mechanisms that cause the photo-oxidation of LDPE films, we propose to use a physically based viscoelasticviscoplastic model to predict the evolution of the mechanical properties. The UV degradation mechanisms of LDPE films were uncovered by means of Fourier transform infrared spectroscopy (FTIR), differential scanning calorimetry (DSC), high-temperature gel permeation chromatography (HT-GPC), and static mechanical characterization. In this work, a physically based constitutive model that couples the amorphous and crystalline phased and the molecular network contributions was altered to include the UV degradation effect. Specifically, the effect of UV radiation on the mechanical behavior of the LDPE films was accounted for in molecular network and the crystalline and amorphous phases by considering the alteration of some material parameters. The pristine distinct constitutive responses of the amorphous and the crystalline phases were identified from Ayoub et al. (2011). The paper is organized as follows. The experimental rheological and mechanical results are discussed in Section 2. The framework of the visco-hyperelastic-viscoplastic constitutive model coupled with photo-degradation kinetics is described in Section 3. Finally, in Section 4 the comparison with the experimental results is presented.

\section{Materials, experimental methods and results}

In this section, a summary of the photo-degradation experimental results, including physico-chemical analysis and mechanical characterization, is provided. The degradation mechanisms are identified and discussed. The purpose of this section is to provide justification of the degradation kinematics integrated into the physical-based model presented in Section 3. The complete physico-chemical, mechanical, and fracture analysis is presented by the authors in detail in Rodriguez et al. (2020).

\subsection{Effect of UV radiation on the physicochemical properties}

Unstabilized (additive-free: no UV stabilizer, anti-blocking agent, slip agent, or antioxidant) low-density polyethylene (LDPE) films of $50 \mu \mathrm{m}$ thickness with $55.5 \%$ crystallinity supplied by Qatar Petrochemical company (QAPCO) were used for this investigation.
The weight-average molecular weight of the LDPE is equal to $M_{w}=$ $164,500 \mathrm{~g} / \mathrm{mol}$, while the number-average molecular weight is equal to $M_{n}=18,200 \mathrm{~g} / \mathrm{mol}$. The LDPE films were UV irradiated using an accelerated weathering device (QUV Weathering Tester, QPanel Lab Products). The device is equipped with fluorescent UVA bulbs simulating the daylight spectral irradiance. The films were exposed to a UV dose of $1.55 \mathrm{~W} / \mathrm{m}^{2}$ at a wavelength of $340 \mathrm{~nm}$, and no control of the humidity rate was used. The films were UV irradiated at variable exposure times of $24,48,72,96$, 192 , and $240 \mathrm{~h}$ at a constant temperature of $60 \pm 2{ }^{\circ} \mathrm{C}$. The $240 \mathrm{~h}$ aging condition corresponds to 3 to 4 months of radiation in outdoor conditions, depending on the region of the world. To understand the UV aging-induced degradation, mechanical and physico-chemical analyses of the UV-irradiated films were conducted. Based on studies from the literature, we are confident that the thickness of the studied LDPE film is less than the reported thickness of oxidized layer (Tavares et al., 2003; Tireau et al., 2009; Hsueh et al., 2020). Therefore, we are confident that the oxidation is homogeneous in the studied specimens.

During the UV-degradation of PE materials, carbonyl groups $(\mathrm{C}=\mathrm{O}$ ) and vinyl groups are formed due to the Norrish type I or II reactions (Gardette et al., 2013; Grigoriadou et al., 2011; Rabek, 1995). Thus, Fourier transform infrared spectroscopy (FTIR) was used in Rodriguez et al. (2020) to study the formation and to determine the concentration of both degradation products in different UV degradation conditions. The classical Beer-Lambert law was used to calculate the concentrations of carbonyl $C_{c}$ and vinyl groups $C_{v}$ (Salivon et al., 2015). Rodriguez et al. (2020) showed that the formation of both degradation products is characterized by an induction period of about $48 \mathrm{~h}$, after which a rapid increase in both the vinyl and carbonyl indexes is observed. These results clearly indicate that both hydroperoxide decomposition and Norrish type I and II reactions are active, which can be translated into an increase in chain scissions.

Differential scanning calorimetry (DSC) was used to determine the progression of the lamellar thickness and the crystallinity ratio. The area under the melting peak was determined graphically on the DSC thermograms. Rodriguez et al. (2020) reported that UV aging prompt the formation of smaller lamellar thickness crystallites. The authors reported that crystallites formation was induced by the thermal aging of the samples at $60{ }^{\circ} \mathrm{C}$. The overall variation of the crystallinity ratio was reported to be small ( $6 \%)$. Although the bulk crystallinity ratio was not impacted by the formation of the smaller lamellar thickness, it was clearly shown that the mechanical behavior was significantly influence when these crystals are homogeneously distributed in the LPDE matrix. It was assumed that those crystallites play a similar role to that of chemical crosslinks.

The effect of the UV-induced chain scissions on the molecular structure was assessed by measuring the change in the molecular weight of the LDPE. High-temperature gel permeation chromatography (HT-GPC) was used to measure the effect of UV radiation doses on the molecular weight of the LDPE. Fig. 1 plots the effect of UV radiation on the number-average $\left(M_{n}\right)$ and weight-average $\left(M_{w}\right)$ molecular weights, and the molecular weight distribution (PDI). Both molecular weight averages decrease with increasing emitted UV doses up to $900 \mathrm{mj} / \mathrm{m}^{2}$, after which an increase is observed. It was assumed that the initial reduction in the average molecular weight is the result of the high activity of chain scission process, while the subsequent increase of the average molecular weight beyond the emitted UV doses of $900 \mathrm{~mJ} / \mathrm{m}^{2}$ is the result of a high activity of crosslinking reaction at the longer term. Furthermore, Rodriguez et al. (2020) suggested that chemi-crystallization of free chain segments generated by chain scissions is active for UV doses lower than $500 \mathrm{~mJ} / \mathrm{m}^{2}$ 


\subsection{UV radiation effect of on the mechanical behavior}

The pristine and photodegraded LDPE films were tensile tested along the film processing direction (PD). The Fig. 2.a inset shows the tensile specimen's geometrical features anticipated to localize the deformation and hence fracture in the center part. The mechanical characterization was achieved using an MTS Insight tensile testing machine (equipped with $1 \mathrm{kN}$ load cell) and a non-contact laser extensometer able to regulate the machine cross-head speed to achieve a local constant strain rate of $0.005 \mathrm{~s}^{-1}$. The mechanical characterization was achieved at room temperature. At least three tests were performed to check the repeatability of the mechanical response. Furthermore, the fullfield strain was measured by utilizing a digital image correlation (DIC) setup by Dantec. For this purpose, a black and white speckle was applied to the tensile specimen to track their displacement. The Istra4D software by Dantec was used for the data processing. The true stress and true strain were calculated after measuring the transverse direction (TD) strain $\varepsilon_{11}$ using the DIC: $\sigma=\frac{F}{S_{0}} \exp \left(-2 \varepsilon_{11}\right)$ with $S_{0}$ is the original cross section, and $F$ is the measured force. The engineering stress and strain were calculate as follow: $\sigma=\frac{F}{S_{0}}, \varepsilon_{\text {eng }}=\frac{L-L_{0}}{L_{0}}$ with $L_{0}$ being the original gage length and $L$ the actual gage length. The specimens that were photodegraded with UV doses higher than $550 \mathrm{~mJ} / \mathrm{m}^{2}$ were too brittle to be tensile tested.

Fig. 2 shows the mechanical response curves of the pristine and photodegraded LDPE. Fig. 2.a shows the engineering stressengineering strain behavior. The pristine film (0 UV dose) exhibits initially an elastic response, followed a successive transition to yield that coincides with the onset of necking. The neck propagation is characterized by a relatively stable plastic stress and a steady strain hardening before the complete failure. The photodegraded films' nominal curves showed a drop of their failure strain, an increase of the yield stress, and higher strain hardening rates. The decrease by $\sim 80 \%$ (between pristine and $536 \mathrm{~mJ} / \mathrm{m}^{2}$ of UV dose films) of nominal strain at failure is related to the photo-oxidationinduced chain scissions. The evolution of the strain-hardening rate with increasing UV dose is characterized by an increase up to a UV dose of $268 \mathrm{~mJ} / \mathrm{m}^{2}$, followed by a decrease. Fig. 2.b shows the true stress-true strain behavior of the pristine and photodegraded LDPE. The DIC system was unable to maintain the correlation at large deformation, therefore impeding the accuracy of the measure-

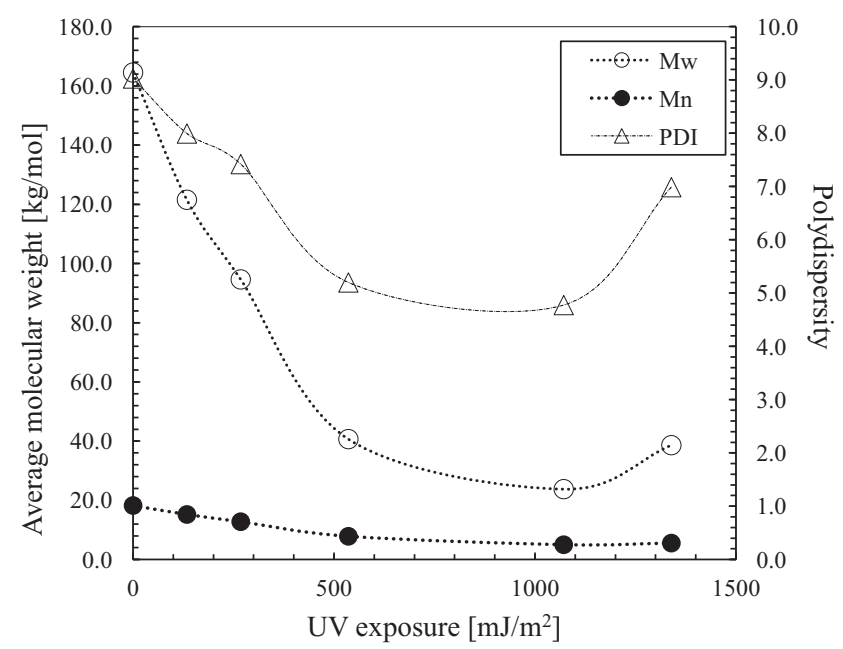

Fig. 1. Evolution of the number average, $M_{n}$, and weight-average, $M_{w}$ molecular weights and the molecular weight distribution (PDI $\left.=M_{w} / M_{n}\right)$ as a function of the UV emitted dose.

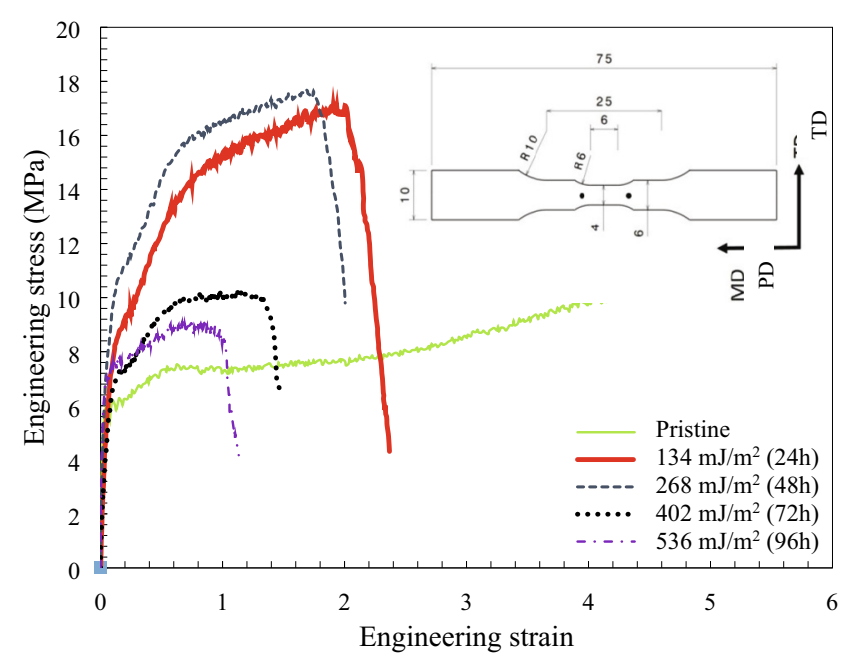

(a)

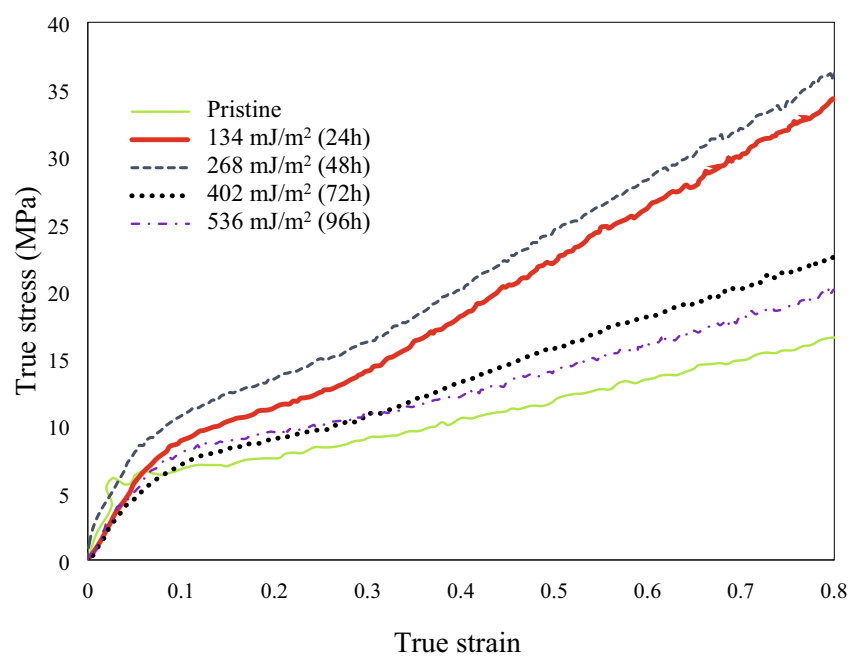

(b)

Fig. 2. As-received and aged materials at different UV emitted dose (a) Engineering stress-engineering strain plots (b) True stress-true strain curves; the inset presents the geometry of the tensile specimen, dimensions in $\mathrm{mm}$.

ments for strains above 0.8 . Similar to the nominal curves, the true curves showed a strengthening induced by the photodegradation. We can observe that with increasing UV dose, the yield stresses and the hardening rates follow the same trend, i.e., increase up to a UV dose of $268 \mathrm{~mJ} / \mathrm{m}^{2}$, followed by a decrease. Those evolutions suggest the presence of competing photo-degradation mechanisms.

Fig. 3 shows the evolution of the yield strength and the true fracture strain as a function of the emitted UV dose. As mentioned earlier, since the DIC system was unable to maintain the correlation at strains above 0.8 , the strains to failure were extracted from the engineering stress-strain curves and converted to true strains. The decrease in the strain to failure with increasing emitted UV dose is associated with the chain scissions evidenced by the decrease in the average molecular weight.

Fig. 4 shows the evolution of the engineering stress at failure and the hardening rate. The hardening rate was determined by calculating the average slope of the true stress-strain curve in the fully established plastic flow. The figure shows that the engineering stress at failure and the hardening rate follow the same evolu- 
tionary trend, with the maximum values reached at around $268 \mathrm{~mJ} / \mathrm{m}^{2}$. The evolution of the yield strength and the hardening rate with increasing UV dose is attributed to the following competing mechanisms: chemi-crystallization, crosslinking, and photodegradation-induced cavitation. Rodriguez et al. (2020) suggested that free chain segments generated from chain scissions crystallize instantly. The decrease in the molecular weight measured through GPC for samples exposed to UV doses below $900 \mathrm{~mJ} / \mathrm{m}^{2}$ is clearly the result of chain scissions. Although a small variation $(\sim 6 \%)$ of the crystallinity ratio was measured with DSC, it was suggested that their homogeneous distribution in the LDPE matrix would affect the mechanical behavior similarly to the formation of chemical crosslinks. Therefore, the increase of the yield stress and the strengthening at UV doses below $268 \mathrm{~mJ} / \mathrm{m}^{2}$ is associated with chemi-crystallization. Furthermore, the limited amount of crosslinking that can be induced by photo-degradation will further contribute to the hardening of the UV-aged LDPE. The rate of chemi-crystallization is suggested to reach a steady state for UV doses of $268 \mathrm{~mJ} / \mathrm{m}^{2}$, and therefore the effect of chain scissions becomes dominant, which effectively counteracts the strengthening effect of the crystallites or crosslinking. Hence, the weakening of the photodegraded LDPE for UV doses above $268 \mathrm{~mJ} / \mathrm{m}^{2}$ is accredited to the network entanglements reduced density. Furthermore, chemical cracks induced by the predominant chain scission degradation mechanism, which contribute further to the weakening of the material, were observed at a later stage of photo-oxidation. The presence of the chemical cracks was evidenced in studying the fracture surface of the tested specimens. While unaged films presented a smooth, damage- and crack-free fracture, UV-aged films presented extensive damage and cracking. Oxidation is restricted to a superficial layer owing to its kinetic control by oxygen diffusion. Oxidation-induced cracking is the result of two sequential scenarios (Colin and Verdu 2012). On the one hand, oxidation leads to an increase in polymer density, due to the incorporation of heavier atoms of oxygen, and to a weight loss, due to the release of volatile compounds. The combination of both phenomena generates a hindered shrinkage, which ultimately causes the development of a tensile stress gradient in the oxidized layer. On the other hand, oxidation generates chain scissions then chemi-crystallization, which are directly responsible for a catastrophic fall of the fracture properties in the oxidized layer. It is thus expected that, when the maximum tensile stress reaches its breaking value (depending on the oxidation progress), a crack is initiated on the surface of the oxidized layer. Hence,

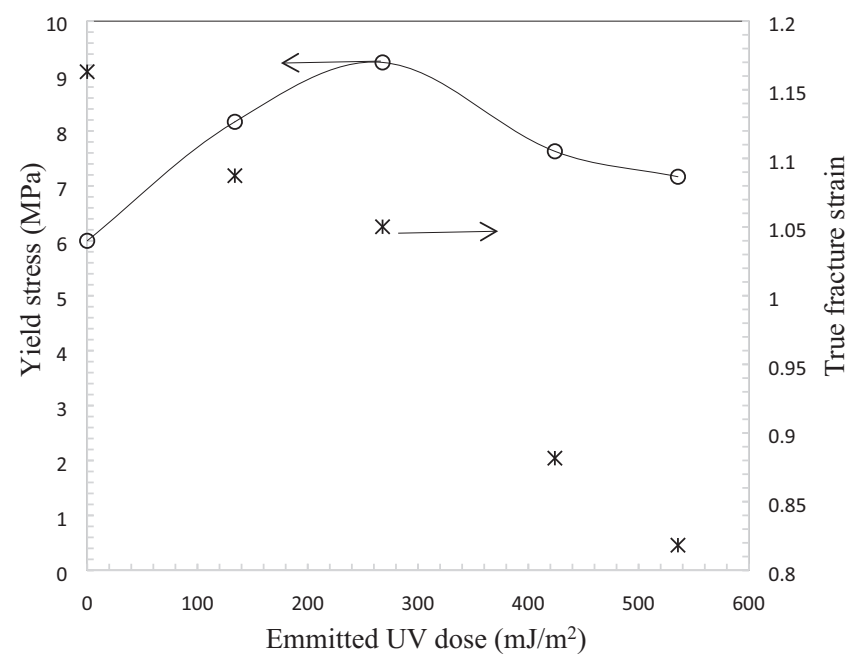

Fig. 3. Effect of photo-degradation on the yield stress and the true fracture strain.

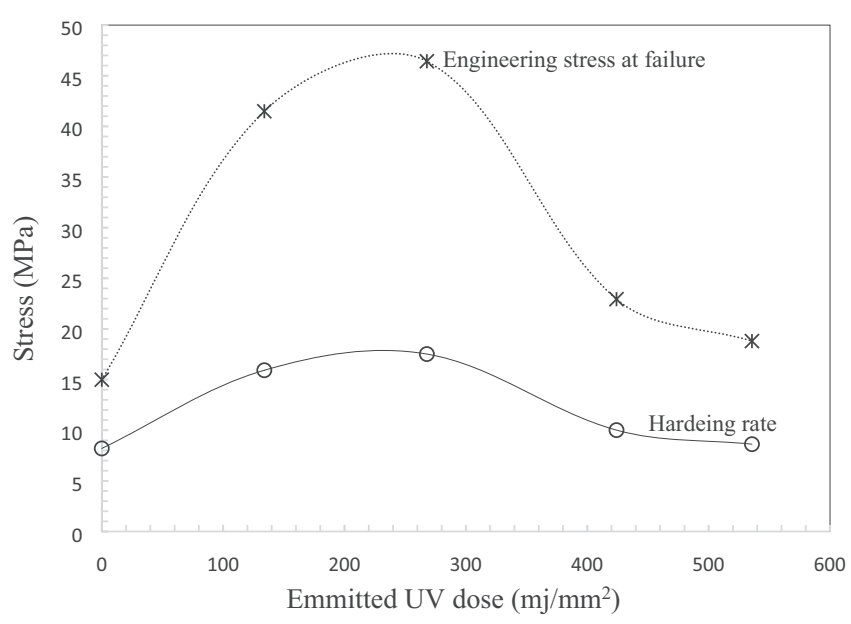

Fig. 4. Effect of photo-degradation on the engineering stress at failure and the hardening rate.

we can assume that photo-degradation-induced cavitation that contributes to the weakening of the LDPE is stimulated by (i) the presence of chemically-induced microcracks that provide nucleation sites for voids, (ii) the development of secondary crystals that lead to an increase of the stress required to deform the crystalline region, and (iii) the decrease in the molecular weight.

Based on all these experimental observations, we assume that the alteration in the mechanical properties of the UV-irradiated materials is the result of a competing multi-scale phenomena namely, at the nano scale, chain scissions and cross-linking and at the meso and macro scales, oxidation-induced cracking, chemi-crystallization, and mechanical damage. Consequently, physical-based models that connect the macroscopic behavior (yielding and strain hardening) to physical macromolecular properties are the best candidates for capturing the degradation induced by UV irradiation. Relying on our understanding of the mechanisms that cause the photo-oxidation of LDPE films, a physically based internal state variable constitutive model that couples the intermolecular and the molecular network contributions was selected and modified to predict the UV degradation effect on the mechanical properties.

\section{Modeling}

In this section, we start by summarizing the theory for finite deformation visco-hyperelastic-viscoplastic modeling. We continue by presenting the constitutive equations incorporating the effect of UV aging. Finally, the experimental and simulation results are compared and discussed.

In this work, the following notation is used. Bold-face symbols are utilized to represent vector and tensor quantities while italics is used to represent individual components of vectors and tensors and scalars. The time derivative is represented by a superposed dot " . ", the double contraction is represented by a bold-face dot ".", the deviatoric quantities are represented by the prime " " " and the transpose quantity is represented by superscript " $T$ ”.

\subsection{Kinematics}

In the reference configuration, let us consider $\boldsymbol{X}$ the position of a material point and $\boldsymbol{x}$ its position in the deformed configuration. The total deformation gradient tensor is then defined as $\boldsymbol{F}=\partial \boldsymbol{X} / \partial \boldsymbol{x}$. The total deformation gradient tensor is written as follows: $\boldsymbol{F}=\boldsymbol{F}^{e} \boldsymbol{F}^{p}$ (Lee, 1969), where $\boldsymbol{F}^{e}$ is the elastic deformation gradient and $\boldsymbol{F}^{p}$ 
is the plastic deformation gradient. The velocity gradient tensor is expressed as $\boldsymbol{L}=\dot{\boldsymbol{F}} \boldsymbol{F}^{-1}$, with the dot denoting the derivation over time, and can be additively decomposed into a rate of deformation tensor $\boldsymbol{D}$ and a spin tensor $\boldsymbol{W}$ as follows: $\boldsymbol{L}=\boldsymbol{D}+\boldsymbol{W}$. Furthermore, the velocity gradient tensor can be additively decomposed into elastic $\boldsymbol{L}^{e}$ and plastic $\boldsymbol{L}^{p}$ velocity gradient tensors as follows: $\boldsymbol{L}=\boldsymbol{L}^{e}+\boldsymbol{L}^{p}$. We can express $\boldsymbol{L}^{e}$ and $\boldsymbol{L}^{p}$ as follows:

$\boldsymbol{L}^{e}=\dot{\boldsymbol{F}}^{e} \boldsymbol{F}^{e^{-1}}=\boldsymbol{D}^{e}+\boldsymbol{W}^{e}$

$\boldsymbol{L}^{p}=\boldsymbol{F}^{e} \dot{\boldsymbol{F}}^{p} \boldsymbol{F}^{\boldsymbol{p}^{-1}} \boldsymbol{F}^{e^{-1}}=\boldsymbol{D}^{p}+\boldsymbol{W}^{p}$

$\boldsymbol{D}^{e}$ and $\boldsymbol{D}^{p}$ are the rate of the elastic and plastic deformation tensors, and $\boldsymbol{W}^{\boldsymbol{e}}$ and $\boldsymbol{W}^{p}$ are the elastic and plastic spin tensors. The incompressibility of the plastic flow is assumed as proposed and debated by Boyce et al. (1989); hence, $\operatorname{det} \boldsymbol{F}^{p}=1$ by assuming an irrotational plastic flow $\boldsymbol{W}^{p}=0$. Consequently, the plastic deformation gradient can be expressed as $\dot{\boldsymbol{F}}^{p}=\boldsymbol{F}^{e^{-1}} \boldsymbol{D}^{p} \boldsymbol{F}^{e} \boldsymbol{F}^{p}=\boldsymbol{F}^{e^{-1}} \boldsymbol{D}^{p} \boldsymbol{F}$.

\subsection{Constitutive equations}

The constitutive model presented in this work is based on the previous work of Boyce et al. (2000), Ahzi et al. (2003), and Ayoub et al. (2011). The deformation in the semi-crystalline polymer is assumed to consist of the contributions of an intermolecular deformation and a network deformation. Moreover, the intermolecular deformation is the contribution of the deformation mechanisms of the crystalline and amorphous phases. The mechanical coupling between both phases' deformation follows a composite framework. A parallel deformation system is considered; hence, the total deformation gradient $\boldsymbol{F}$ is taken as equal to the network $\boldsymbol{F}_{N}$ and intermolecular $\boldsymbol{F}_{l}$ deformation gradients. Based on the aforementioned, the total Cauchy stress $\boldsymbol{T}$ is the sum of the network $\boldsymbol{T}_{N}$ and intermolecular $\boldsymbol{T}_{I}$ Cauchy stresses: $\boldsymbol{T}=\boldsymbol{T}_{N}+\boldsymbol{T}_{I}$.

\subsubsection{Intermolecular contribution:}

The deformation mechanisms considered in this part are the visco-elastoplastic behavior of the amorphous and the crystalline phases. A parallel deformation system is assumed to represent the contributions of both the amorphous and the crystalline phases to the intermolecular deformation. The deformation gradient of the crystalline phase $\boldsymbol{F}_{I}^{c}$ and the amorphous phase $\boldsymbol{F}_{I}^{a}$ is equal to the intermolecular deformation gradient $\boldsymbol{F}_{I}$. The overall intermolecular Cauchy stress $\boldsymbol{T}_{I}$ is expressed as a modified mixture rule:

$\boldsymbol{T}_{I}=\left(\chi_{c v}\right)^{\eta} \boldsymbol{T}_{I}^{c}+\left(1-\chi_{c v}\right)^{\eta} \boldsymbol{T}_{I}^{a}$

where $\boldsymbol{T}_{I}^{i}$ represents the Cauchy stresses of the amorphous and crystalline phases, with $i$ referring to the considered phase ("a" for amorphous and "c" for crystalline); $\chi_{c v}$ is the crystal volume fraction; and $\eta$ is a parameter representing the interaction between the two phases, equal to 3.8. Ayoub et al. (2011) justified the need for the modified mixture rule by the nonlinear evolution of the elastic modulus vs. the crystal content that can't be captured using a linear mixture rule. The Cauchy stress is expressed as $\boldsymbol{T}_{I}^{i}=1 / J_{I}^{i}\left(\mathbb{C}_{I}^{e_{-} i} \ln \left(\boldsymbol{V}_{I}^{e-i}\right)\right)$, where $J_{I}^{i}=\operatorname{det} \boldsymbol{F}_{I}^{e-i}$ is the volume change induced by the elastic deformation, $\ln \left(\boldsymbol{V}_{I}^{e_{i} i}\right)$ is the Hencky strain, $\boldsymbol{V}_{I}^{e \_} i$ is the elastic stretch component of elastic deformation gradient polar decomposition, and $\mathbb{C}_{I}^{e_{-} i}$ is the elastic stiffness tensor expressed by:

$$
\left(\mathbb{C}_{I}^{e-i}\right)_{i j k l}=\frac{E^{i}}{2\left(1+v^{i}\right)}\left[\left(\delta_{i k} \delta_{j l}+\delta_{i l} \delta_{j k}\right)+\frac{2 v^{i}}{1-2 v^{i}} \delta_{i j} \delta_{k l}\right]
$$

The Kronecker-delta symbol is represented by $\delta, E^{i}$ is the elastic modulus, and $v^{i}$ is the Poisson's ratio. The flow rule is expressed through the viscoplastic strain rate tensor in each phase $\boldsymbol{D}_{I}^{p \_i}$ as follows:

$\boldsymbol{D}_{I}^{p_{\perp} i}=\dot{\gamma}_{I}^{p_{-} i} \frac{\boldsymbol{T}_{I}^{\prime i}}{\sqrt{2} \tau_{I}^{i}}$

where $\boldsymbol{T}_{I}^{i}=\boldsymbol{T}_{I}^{i}-\operatorname{trace}\left(\boldsymbol{T}_{I}^{i}\right) / 3 \boldsymbol{I}$ is the deviatoric part of the Cauchy stress tensor, $\tau_{I}^{i}=\left(\boldsymbol{T}_{I}^{\prime i} \cdot \boldsymbol{T}_{I}^{\prime i} / 2\right)^{1 / 2}$ is the effective stress, and $\dot{\gamma}_{I}^{p_{-} i}$ is the plastic shear rate expressed as:

$\dot{\gamma}_{I}^{p-i}=\dot{\gamma}_{0, I}^{i} \exp \left[-\frac{\Delta G_{I}^{i}}{k \theta}\left(1-\frac{\tau_{I}^{i}}{\tau_{0}^{i}}\right)\right]$

where $\Delta G_{I}^{i}$ is the activation energy, $\dot{\gamma}_{0, I}^{i}$ is the reference shear rate, $k$ is the Boltzmann constant, and $\theta$ is the temperature in Kelvin. $\tau_{0}^{i}$ is the critical resolved shear stress that evolves with the plastic flow by assuming that $\dot{\tau}_{0}^{i}=h^{i} \dot{\gamma}_{I}^{p_{-} i}$, the hardening rate $h^{i}=\tau_{0}^{i} / n^{i}\left(\kappa \tau_{y}^{i} / \tau_{0}^{i}\right)^{n^{i}}, \tau_{y}^{i}$ is the initial critical shear stress, $n^{i}$ is a coefficient of hardening, and $\kappa$ is a parameter associated with the crystal morphology, with its evolution described in Ayoub et al. (2011).

\subsubsection{Network contribution:}

The deformation mechanisms accounted for in this part are the change in the entropy induced by the alignment of molecular network along the loading direction (Arruda and Boyce, 1993) and the chain reptation (Bergström and Boyce, 1998; Boyce et al., 2000). Although semi-crystalline polymers are studied, it is assumed that the molecular orientation dominates the strain-hardening response rather than crystallographic orientation.

The network Cauchy stress tensor is expressed using the eightchain model proposed by Arruda and Boyce (1993):

$\boldsymbol{T}_{N}=\frac{1}{J_{N}} \frac{n_{c} k \theta}{3} \frac{\sqrt{N}}{\bar{\lambda}_{N}^{e}} \mathscr{L}^{-1}\left(\frac{\bar{\lambda}_{N}^{e}}{\sqrt{N}}\right)\left[\overline{\boldsymbol{B}}^{e}-\left(\bar{\lambda}_{N}^{e}\right)^{2} \boldsymbol{I}\right]$

where $J_{N}=\operatorname{det} \boldsymbol{F}_{N}^{e}$ is the volume change induced by the network elastic deformation; $n_{c}$ is the average chain density; $\sqrt{N}$ is associated with the chain extensibility limit, with $N$ being the number of rigid links between entanglements; $\mathscr{L}(x)=\operatorname{coth}(x)-1 / x$ is the Langevin function, and its inverse can approximated by the Padé approximation (Cohen, 1991) as $\mathscr{L}^{-1}=x\left(3-x^{2}\right) /\left(1-x^{2}\right) ; \quad I$ is the unit matrix; and the average stretch on the network chains defined by $\bar{\lambda}_{N}^{e}=\left[\operatorname{trace}\left(\overline{\boldsymbol{B}}^{e}\right) / 3\right]^{1 / 2}$, with $\overline{\boldsymbol{B}}^{e}=\left(J_{N}\right)^{-2 / 3} \boldsymbol{F}_{N}^{e}\left(\boldsymbol{F}_{N}^{e}\right)^{T}$, is the isochoric left Cauchy-Green tensor. The slope of the stress-strain response after plastic yielding is defined as the hardening modulus $C_{r}=n_{c} k \theta$. The flow strain rate $\boldsymbol{D}_{N}^{p}$ is described by the following flow rule:

$\boldsymbol{D}_{N}^{p}=\dot{\gamma}_{N}^{p} \frac{\boldsymbol{T}_{N}^{\prime}}{\sqrt{2} \tau_{N}}$

where $\boldsymbol{T}_{N}^{\prime}=\boldsymbol{T}_{N}-\operatorname{trace}\left(\boldsymbol{T}_{N}\right) / 3$ Iis the deviatoric part of the network Cauchy stress tensor, $\tau_{N}=\left(\boldsymbol{T}_{N}^{\prime} \cdot \boldsymbol{T}_{N}^{\prime} / 2\right)^{1 / 2}$ is the effective stress, and $\dot{\gamma}_{N}^{p}$ is the viscoplastic shear strain rate, expressed as follows (Bergström and Boyce, 1998):

$\dot{\gamma}_{N}^{p}=C\left(\frac{1}{\lambda_{N}^{p}-1}\right) \tau_{N}$

where $\lambda_{N}^{p}=\left[\operatorname{trace}\left(\boldsymbol{F}_{N}^{p}\left(\boldsymbol{F}_{N}^{p}\right)^{T}\right) / 3\right]^{1 / 2}$, Eq. (9) have a singularity for $\lambda_{N}^{p}=1$ hence, in order to ensure numerical stability a perturbation 
coefficient $v$ is added to $\lambda_{N}^{p}(v=0.01$ is taken throughout our simulations). and $C$ is a temperature dependence relaxation parameter (Boyce et al., 2000) defined as: $C=D \exp (-Q / R \theta)$, in which $D$ and $\mathrm{Q}$ are two material parameters and $\mathrm{R}$ is the universal gas constant.

\subsubsection{Photo-degradation kinematics:}

The photo-degradation effect is accounted for in the constitutive equations by considering the alteration of some material parameters. The elementary chemical mechanisms are not considered in our approach. The experimental results show an alteration of the molecular network as the average molecular weight is strongly affected by the UV irradiation. The length of the molecular chains is implicitly accounted for by the network part of the constitutive equations. Furthermore, the evolution of the crystallinity ratio and the yield strength should be accounted for in the intermolecular part of the constitutive equations. As suggested by Belbachir et al. (2010) the molecular weight is taken as the UVaging representative variable, and therefore the photodegradation parameter is expressed as follows:

$\beta=1-\frac{M_{w}}{M_{w 0}}$

where $M_{w}$ and $M_{w 0}$ are the current and initial average molecular weights, respectively.

The evolution of the crystallinity ratio $\chi_{c v}$ measured from the DSC thermograms is described by the following equation:

$\chi_{r}=\chi_{r 0}\left(1+0.2 \beta^{5}\right)$

From the experimental and rheological observations, we assume the existence of competing mechanisms, such as chemicrystallization, crosslinking, and initiation and development of chemical cracks. Indeed, it is suggested that chain scissions result in the formation of free chain segments that crystalize instantly. The chain scissions affect the ductility of the LDPE films, which decreases with increasing UV exposure. Furthermore, the small increase in the crystallinity ratio does not alone justify the larger increase in the yield strength and the hardening rate of the UVaged LDPE. It was suggested that the homogeneous distribution of the photo-degradation-induced crystallites in the LDPE matrix would affect the mechanical behavior similarly to the formation of crosslinks. Hence, it will contribute to the increase in the yield strength and the hardening rate. Additionally, a small amount of crosslinking was measured, which can contribute further to the strengthening of the UV-aged LDPE. Finally, the weakening of the UV-aged LDPE after absorption of a UV dose threshold was attributed to photo-degradation-induced cracks. The effect of photodegradation on the molecular network was accounted for by proposing adequate evolutions of the effective number of rigid links between entanglement $N$ and the the hardening modulus $C_{r}=n_{c} k \theta$.

$N=N_{\text {chainsession }}+N_{\text {crystal+crosslinking }}$

where $N_{\text {chainsession }}=339.89 e^{-8.5 \beta}$ is the effective number of rigid links between entanglement of a fictive network in which only chain scissions are assumed active. This part of the equation decreases with an increasing photo-degradation parameter, since chain scissions result in a smaller number of rigid links between entanglements. $N_{\text {crystal+crosslinking }}=10 e^{4.2 \beta}$ is the effective number of rigid links between entanglement of a fictive network in which only chemi-crystallization and crosslinking are assumed active. The right part of Eq. (12) increases with an increasing photo-degradation parameter, since crystallization and crosslinking act as nodes between chains and therefore increase the number of monomers between entanglements. The principle of mass conservation of a physical system requires that the product between $C_{r}$ and $N$ be constant, and therefore $C_{r}=C_{r 0} N_{0} / N$.

The effect of photo-degradation on the intermolecular part (the crystalline and the amorphous phases) was accounted for by first considering the hardening resulting from the chemicrystallization and crosslinking, using the following empirical expression:

$H=1+5.8 \beta^{2.2}$

Second, the weakening of the UV-aged LDPE resulting from photo-degradation-induced cavitation was accounted for by the introduction of a damage parameter that evolves as follows:

$D=0.055\left(-1+e^{3.5 \beta}\right)$

Therefore, the evolution of the activation energy $\Delta G$ and the initial shear strengths of the amorphous $s_{a}$ and crystalline $s_{c}$ phases are described by the following expressions:

$$
\begin{aligned}
\Delta G_{I}^{a} & =\Delta G_{I 0}^{a}(1-D) H \\
\Delta G_{I}^{c} & =\Delta G_{I 0}^{c}(1-D) H
\end{aligned}
$$

And:

$$
\begin{aligned}
& s_{a}=\kappa s_{a 0}(1-D) H \\
& s_{c}=\kappa s_{c 0}(1-D) H
\end{aligned}
$$

$\kappa$ is a scale factor that accounts for the crystal morphology evolution with the crystallinity ratio. The evolution of $\kappa$ as a function of the crystallinity ratio was proposed by Ayoub et al. (2011) as follows: $\kappa=190.4 \exp \left(-7.6 \chi_{\mathrm{r}}\right)$. $s_{a 0}$ and $s_{c 0}$ are the pristine LDPE's initial shear strengths of the amorphous and crystalline phases, respectively. Fig. 5 presents the normalized evolutions of the activation energy and the initial shear stress. Those evolutions are considered identical for the crystalline and amorphous phases. Fig. 5 highlights the purpose of the proposed evolution in accounting for the effect of UV aging, which leads initially to an increase in the yielding and the hardening followed by a decrease after a threshold of $\beta=0.6$.

The evolution of the critical strain at break is expressed by the following equation:

$\epsilon_{f}=\epsilon_{f 0}\left(1-0.65 \beta^{2.2}\right)$

where $\epsilon_{f 0}$ is the strain at break of the pristine LDPE. Fracture in polymeric materials is attributed to the breakage of chains that

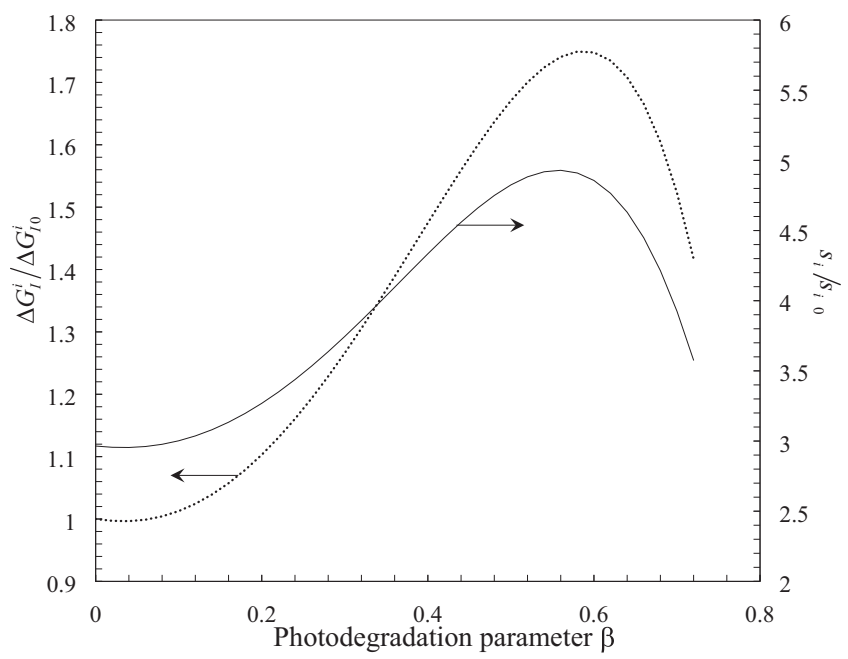

Fig. 5. Evolution of the normalized activation energy and the normalized initial shear strengths. 


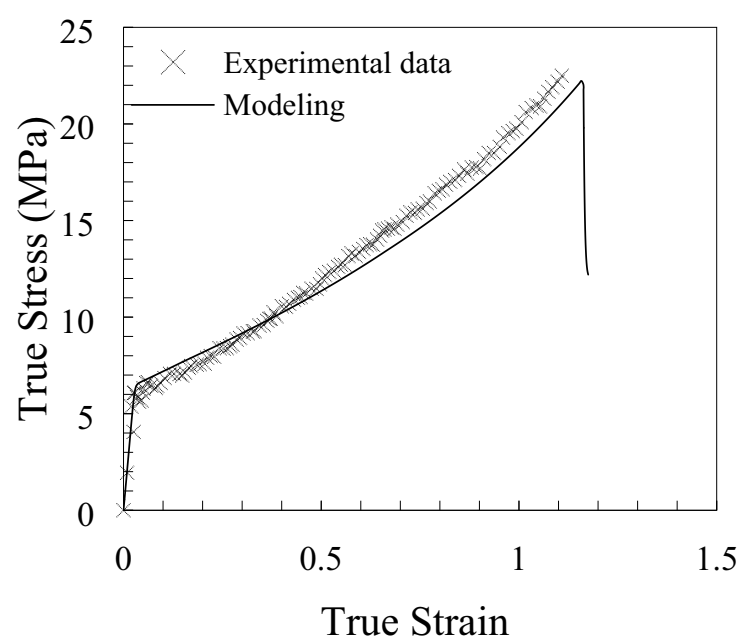

(a)

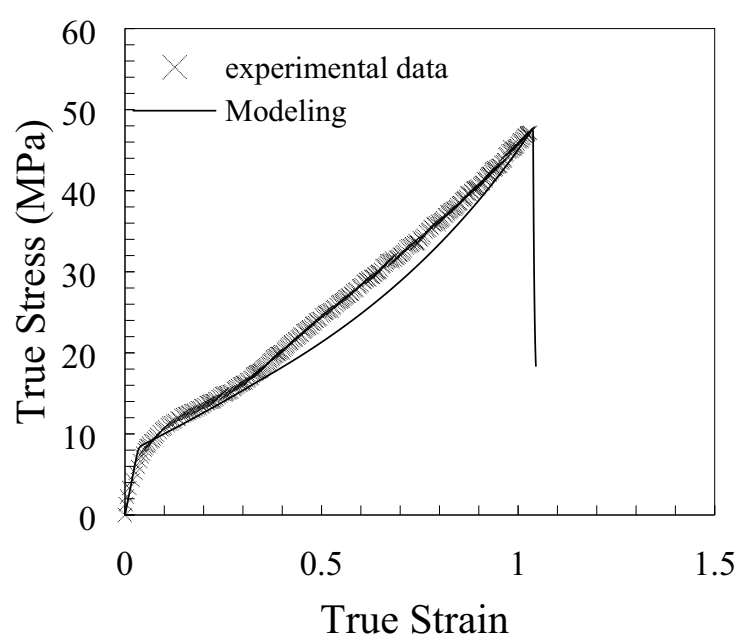

(c)

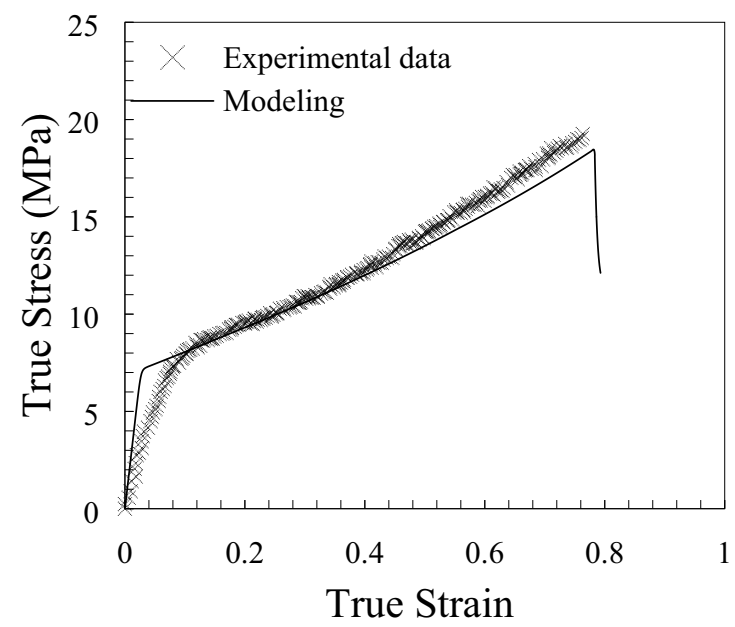

(e)

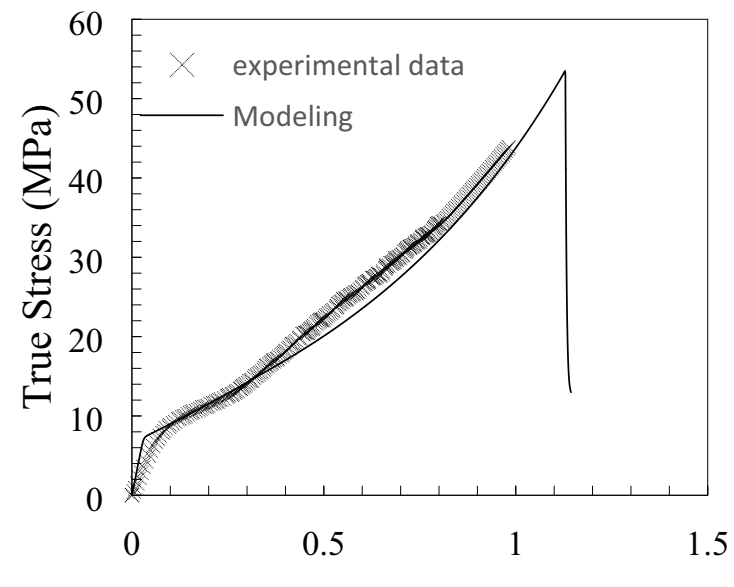

True Strain

(b)

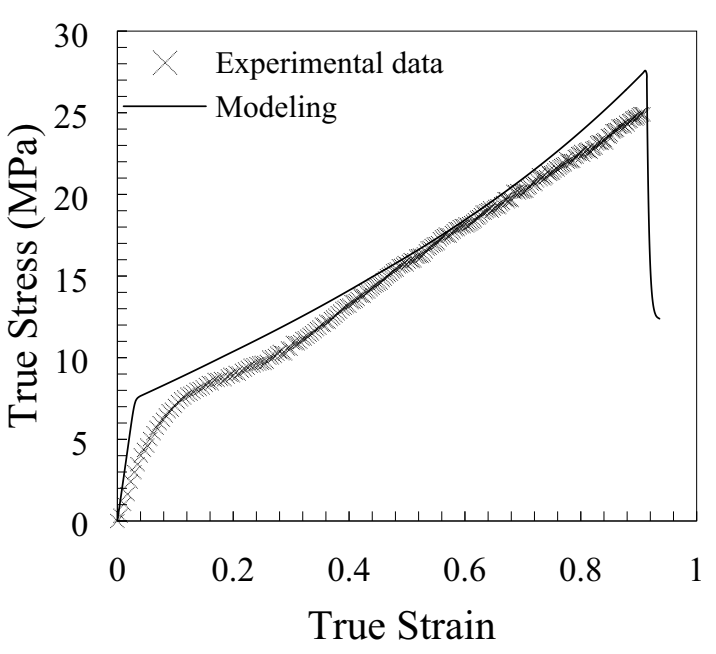

(d)

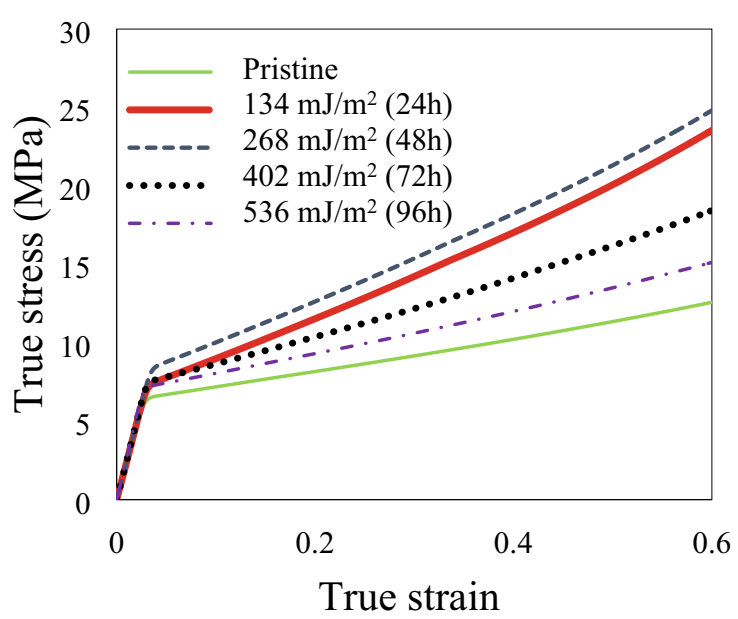

(f)

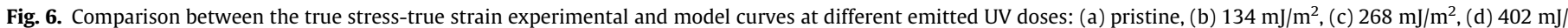
$\mathrm{m}^{2}$, and (e) $536 \mathrm{~mJ} / \mathrm{m}^{2}$ finally (f) presents the predicted true stress-true strain curves of the all the photo-degradation conditions. 


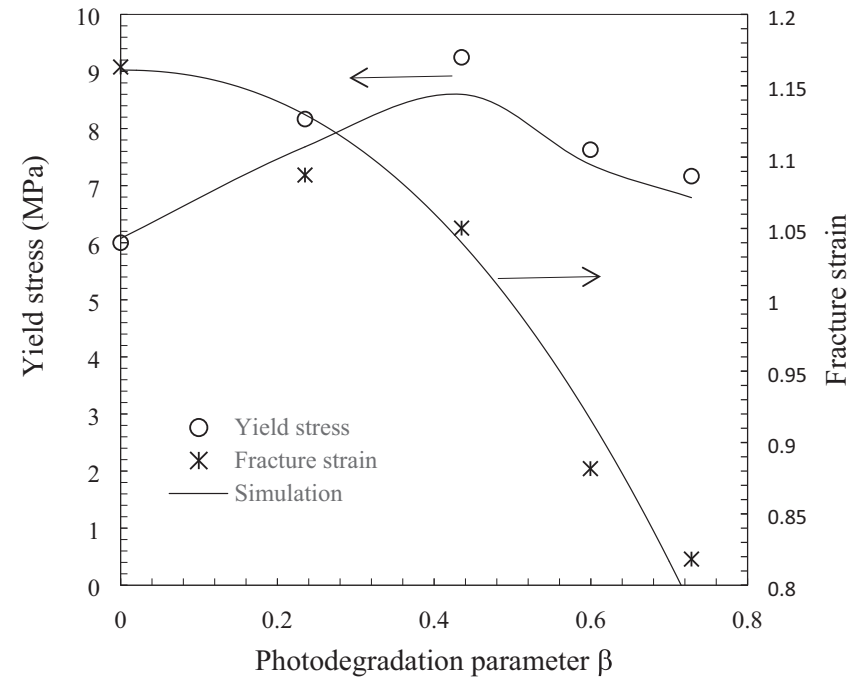

Fig. 7. Comparison between the experimental and simulation results of the yield stress and fracture strain as a function of the photo-degradation parameter.

have reached their limit of extensibility. To simulate the fracture in the stress-strain curve, we assume a drastic decrease in the stiffness of the network by increasing $N$ and decreasing $C_{r}$ as follows:

$N_{t}=\left\{\begin{array}{cl}N & \text { if } \lambda<\lambda_{f} \\ \operatorname{Nexp}\left(\alpha\left(\lambda-\lambda_{f}\right)\right) & \text { if } \lambda \geq \lambda_{f}\end{array}\right.$

With $\lambda$ being the stretch along the loading direction and $\lambda_{f}$ the stretch at break. The principle of mass conservation of a physical system is used to determine $C_{r}$.

The proposed the visco-hyperelastic-viscoplastic constitutive model coupled with photo-degradation kinetics was implemented as a standalone code written in Fortran. A backward Euler's method was used to numerically integrate the three dimensional mathematical framework. To replicate the experimental constant true strain rate tensile loading the deformation gradient tensor was written as:

$F=\left(\begin{array}{ccc}e^{\dot{\varepsilon} \tau} & 0 & 0 \\ 0 & e^{-\dot{\varepsilon} \tau / 2} & 0 \\ 0 & 0 & e^{-\dot{\varepsilon} \tau / 2}\end{array}\right)$

where $\dot{\varepsilon}$ is the strain rate and $\tau$ is the time.

\section{Discussion and results}

The pristine material $(\beta=0)$ is a semicrystalline LDPE, and therefore, we used the deterministic identification scheme elaborated under different strain rates and crystallinity ratios by

Table 1

Material constants for the intermolecular part.

$\begin{array}{lll}\text { Amorphous phase elastic modulus } & E^{a} & 4.5(\mathrm{MPa}) \\ \text { Crystalline phase elastic modulus } & E^{c} & 4500(\mathrm{MPa}) \\ \text { Phases interaction coefficient } & \eta & 3.8 \\ \text { Reference shear rate } & \dot{\gamma}_{0, I}^{a}=\dot{\gamma}_{0, I}^{c} & 10-6\left(\mathrm{~s}^{-1}\right) \\ \text { Amorphous phase activation energy } & \Delta G_{I 0}^{a} & 7.410-20(\mathrm{~J}) \\ \text { Crystalline phase activation energy } & \Delta G_{I 0}^{c} & 1.110-20(\mathrm{~J}) \\ \text { Initial amorphous critical shear stress } & s_{a 0} & 0.055(\mathrm{MPa}) \\ \text { Initial crystalline critical shear stress } & s_{c 0} & 4.7(\mathrm{MPa}) \\ \text { Amorphous phase hardening coefficient } & n^{a} & 1.4 \\ \text { Crystalline phase hardening coefficient } & n^{c} & 193\end{array}$

Ayoub et al. (2011) to identify the constitutive response of the considered phases. Table 1 lists the parameters of the constitutive responses of the crystalline and amorphous phases. Therefore, the visco-elastoplastic response of the intermolecular resistance can be determined for any PE by using the same set of parameters identified by Ayoub et al. (2011) and by computing only the exact crystallinity ratio. In this work, Table 1 parameters were used combined with the photo-degradation kinematic Eqs. (11)-(18) to describe the effect of UV irradiation on the mechanical behavior of LDPE films.

Fig. 6 shows the capability of the proposed model to capture the mechanical true stress-true strain behavior of the LDPE at different levels of UV irradiation doses (The strain quantities are model input, since the true strain is determined as $\varepsilon=\dot{\varepsilon} \tau=\ln \left(\frac{L}{L_{0}}\right)$ and the stresses are the Cauchy stress given in Eq. (3)). The model is able to capture the different features of the mechanical response and its evolution with increasing UV dosage. The proposed model is able to depict the evolution of the yielding and the strainhardening rate characterized by an increase with increasing UV dose up to $268 \mathrm{~mJ} / \mathrm{m}^{2}$, followed by a decrease. The strain to fracture is also captured accurately; fracture was not observed in Fig. 6 for all the aging conditions, since the DIC system lost correlation. However, the predicted strain to fracture was calibrated on the data presented in Fig. 3. A qualitative comparison between the model predictions and the experimental results of the yield stress and fracture strain evolutions as a function of the photodegradation parameter is presented in Fig. 7. It is clearly highlighted that the model results fit the experimental evolutions well.

\section{Conclusion}

In this work, the effect of UV aging on the mechanical behavior of semi-crystalline low-density polyethylene (LDPE) films was studied. The UV degradation mechanisms of LDPE films were uncovered using an extensive experimental characterization campaign, specifically by analyzing the UV-aged specimens with Fourier transform infrared spectroscopy (FTIR), differential scanning calorimetry (DSC), high-temperature gel permeation chromatography (HT-GPC), and static mechanical characterization. Based on all the experimental observations, we assumed that the alteration in the mechanical properties of the UV-irradiated materials is the result of competing multi-scale phenomena, namely, chain scissions and crosslinking at a fine scale and chemi-crystallization, oxidation-induced cracking, and mechanical damage at the meso and coarse scales. Consequently, a physical-based model connecting the macroscopic behavior (yielding and strain hardening) to the physical macromolecular properties was proposed to capture the effect of UV irradiation. Hence, the evolution of the mechanical behavior of the LDPE film was considered the result of the individual constitutive response evolutions of the crystalline and amorphous phases coupled with the constitutive response evolution of the molecular network. The pristine individual constitutive responses of the crystalline and amorphous phases were found to follow the one identified by Ayoub et al. (2011). The photodegradation effect was incorporated into the constitutive model to capture the macroscopically observed mechanical behavior. The gel permeation chromatography-measured molecular weight was used as a direct input into the model. The model shows good agreement with the experimental results over a wide range of UV irradiation doses. The model was capable of capturing the different features of the mechanical response and their evolution with increasing UV dosage. The proposed model assumed that the stiffness was affected only by the evolution of the crystallinity ratio. Although the assumption was not validated, since measuring the stiffness from global stress-strain curves is not accurate, the mod- 
el's predictions of the elastic behavior of the pristine and UV-aged LDPE films were acceptable. Finally, the authors believe that the usage of strain gauges would be essential for accurate measurements of the stiffness evolution with increasing UV exposure.

\section{Declaration of Competing Interest}

The authors declare that they have no known competing financial interests or personal relationships that could have appeared to influence the work reported in this paper.

\section{Acknowledgements}

This research was supported by the Qatar National Research Fund (NPRP grant No. 7-1562-2-571). We would like to acknowledge the fruitful discussions with Prof. Amine Benzerga of Texas A\&M University.

\section{References}

Adams, A.M., Buckley, C.P., Jones, D.P., 2000. Biaxial hot drawing of poly(ethylene terephthalate): measurements and modelling of strain-stiffening. Polymer (Guildf). 41, 771-786. https://doi.org/10.1016/S0032-3861(98)00834-9.

Ahzi, S., Makradi, A., Gregory, R.V., Edie, D.D., 2003. Modeling of deformation behavior and strain-induced crystallization in poly(ethylene terephthalate) above the glass transition temperature. Mech. Mater. 35, 1139-1148. https:// doi.org/10.1016/S0167-6636(03)00004-8.

Anand, L., Ames, N.M., 2006. On modeling the micro-indentation response of an amorphous polymer. Int. J. Plast. 22, 1123-1170. https://doi.org/10.1016/j. ijplas.2005.07.006

Anand, L., Gurtin, M.E., 2003. A theory of amorphous solids undergoing large deformations, with application to polymeric glasses. Int. J. Solids Struct. 40, 1465-1487. https://doi.org/10.1016/S0020-7683(02)00651-0.

Arruda, E.M., Boyce, M.C., 1993. A three-dimensional constitutive model for the large stretch behavior of rubber elastic materials. J. Mech. Phys. Solids 41, 389412. https://doi.org/10.1016/0022-5096(93)90013-6.

Arruda, E.M., Boyce, M.C., Jayachandran, R., 1995. Effects of strain rate, temperature and thermomechanical coupling on the finite strain deformation of glassy polymers. Mech. Mater. 19, 193-212. https://doi.org/10.1016/0167-6636(94) 00034-E.

Ayoub, G., Zaïri, F., Fréderix, C., Gloaguen, J.M., Naït-Abdelaziz, M., Seguela, R., Lefebvre, J.M., 2011. Effects of crystal content on the mechanical behaviour of polyethylene under finite strains: experiments and constitutive modelling. Int. J. Plast. 27. https://doi.org/10.1016/j.ijplas.2010.07.005.

Ayoub, G., Zaïri, F., Naït-Abdelaziz, M., Gloaguen, J.M., 2010. Modelling large deformation behaviour under loading-unloading of semicrystalline polymers: application to a high density polyethylene. Int. J. Plast. 26. https://doi.org/ 10.1016/j.ijplas.2009.07.005.

Balieu, R., Lauro, F., Bennani, B., Delille, R., Matsumoto, T., Mottola, E., 2013. A fully coupled elastoviscoplastic damage model at finite strains for mineral filled semi-crystalline polymer. Int. J. Plast. 51, 241-270. https://doi.org/10.1016/j. ijplas.2013.05.002.

Bardenhagen, S.G., Stout, M.G., Gray, G.T., 1997. Three-dimensional, finite deformation, viscoplastic constitutive models for polymeric materials. Mech. Mater. 25, 235-253. https://doi.org/10.1016/S0167-6636(97)00007-0.

Belbachir, S., Zaïri, F., Ayoub, G., Maschke, U., Naït-Abdelaziz, M., Gloaguen, J.M., Benguediab, M., Lefebvre, J.M., 2010. Modelling of photodegradation effect on elastic-viscoplastic behaviour of amorphous polylactic acid films. J. Mech. Phys. Solids 58. https://doi.org/10.1016/j.jmps.2009.10.003.

B.H. Hamouda H., Laiarinandrasana, L., Piques, R., Viscoplastic behaviour of a medium density polyethylene (MDPE): Constitutive equations based on double nonlinear deformation model Int. J. Plast. 23200713071327 10.1016/j. ijplas.2006.11.007

Bergström, J.S., Boyce, M.C., 1998. Constitutive modeling of the large strain timedependent behavior of elastomers. J. Mech. Phys. Solids 46, 931-954. https:// doi.org/10.1016/S0022-5096(97)00075-6.

Billon, N., 2012. New constitutive modeling for time-dependent mechanical behavior of polymers close to glass transition: fundamentals and experimental validation. J. Appl. Polym. Sci. 125, 4390-4401. https://doi.org/ 10.1002/app.36598.

Boyce, M.C., Parks, D.M., Argon, A.S., 1988. Large inelastic deformation of glassy polymers. part I: rate dependent constitutive model. Mech. Mater. 7, 15-33. https://doi.org/10.1016/0167-6636(88)90003-8.

Boyce, M.C., Weber, G.G., Parks, D.M., 1989. On the kinematics of finite strain plasticity. J. Mech. Phys. Solids. 37, 647-665. https://doi.org/10.1016/00225096(89)90033-1.

Boyce, M.C., Socrate, S., Llana, P.G., 2000. Constitutive model for the finite deformation stress-strain behavior of poly(ethylene terephthalate) above the glass transition. Polymer (Guildf). 41, 2183-2201. https://doi.org/10.1016/ S0032-3861(99)00406-1.
Breche, Q., Chagnon, G., Machado, G., Girard, E., Nottelet, B., Garric, X., Favier, D. 2016a. Mechanical behaviour's evolution of a PLA-b-PEG-b-PLA triblock copolymer during hydrolytic degradation. J. Mech. Behav. Biomed. Mater. 60, 288-300. https://doi.org/10.1016/j.jmbbm.2016.02.015.

Breche, Q., Chagnon, G., Machado, G., Nottelet, B., Garric, X., Girard, E., Favier, D. 2016b. A non-linear viscoelastic model to describe the mechanical behavior's evolution of biodegradable polymers during hydrolytic degradation. Polym. Degrad. Stab. 131, 145-156. https://doi.org/10.1016/j. polymdegradstab.2016.07.014.

Briassoulis, D., Aristopoulou, A., Bonora, M., Verlodt, I., 2004. Degradation characterisation of agricultural low-density polyethylene films. Biosyst. Eng 88, 131-143. https://doi.org/10.1016/j.biosystemseng.2004.02.010.

Brooks, N.W.J., Duckett, R.A., Ward, I.M., 1998. Temperature and strain-rate dependence of yield stress of polyethylene. J. Polym. Sci. Part B Polym. Phys. 36, 2177-2189. https://doi.org/10.1002/(SICI)1099-0488(19980915) 36:12<2177::AID-POLB15>3.0.CO;2-X.

Buckley, C.P., Jones, D.C., 1995. Glass-rubber constitutive model for amorphous polymers near the glass transition. Polymer (Guildf). 36, 3301-3312. https:// doi.org/10.1016/0032-3861(95)99429-X.

Carrasco, F., Pagès, P., Pascual, S., Colom, X., 2001. Artificial aging of high-density polyethylene by ultraviolet irradiation. Eur. Polym. J. 37, 1457-1464. https:// doi.org/10.1016/S0014-3057(00)00251-2.

Cayzac, H.-A., Saï, K., Laiarinandrasana, L., 2013. Damage based constitutive relationships in semi-crystalline polymer by using multi-mechanisms model. Int. J. Plast. 51, 47-64. https://doi.org/10.1016/j.ijplas.2013.06.008.

Chabira, S.F., Sebaa, M., Huchon, R., De Jeso, B., 2006. The changing anisotropy character of weathered low-density polyethylene films recognized by quasistatic and ultrasonic mechanical testing. Polym. Degrad. Stab. 91, 1887-1895. https://doi.org/10.1016/j.polymdegradstab.2005.11.007.

Cohen, A., 1991. A Padé approximant to the inverse Langevin function. Rheol. Acta 30, 270-273. https://doi.org/10.1007/BF00366640.

Colak, O.U., 2005. Modeling deformation behavior of polymers with viscoplasticity theory based on overstress. Int. J. Plast. 21, 145-160. https://doi.org/10.1016/j. ijplas.2004.04.004.

Colin, X., Verdu, J., 2012. Aging of organic matrix composite material, in: Wiley Encyclopedia of Composites, 2nd Edition, vol. 1/5, L. Nicolais, A. Borzacchiello and S.M. Lee eds, John Wiley \& Sons Ltd, New York, Chap. 4, pp. 35-49.

Craig, I.H., White, J.R., 2005. Crystallization and chemi-crystallization of recycled photodegraded polyethylenes. Polym. Eng. Sci. 45, 588-595. https://doi.org 10.1002/pen.20314.

Detrez, F., Cantournet, S., Séguéla, R., 2010. A constitutive model for semi-crystalline polymer deformation involving lamellar fragmentation. Comptes Rendus Mécanique 338, 681-687. https://doi.org/10.1016/j.crme.2010.10.008.

Drozdov, A.D., 2010. Cyclic thermo-viscoplasticity of high density polyethylene. Int J. Solids Struct. 47, 1592-1602. https://doi.org/10.1016/j.ijsolstr.2010.02.021.

Drozdov, A.D., 2009. Mullins' effect in semicrystalline polymers. Int. J. Solids Struct 46, 3336-3345. https://doi.org/10.1016/j.ijsolstr.2009.05.001.

Drozdov, A.D., Christiansen, J. de C., 2007. Cyclic viscoplasticity of high-density polyethylene: Experiments and modeling. Comput. Mater. Sci. 39, 465-480. https://doi.org/10.1016/j.commatsci.2006.07.014.

Drozdov, A.D., Gupta, R.K., 2003. Constitutive equations in finite viscoplasticity of semicrystalline polymers. Int. J. Solids Struct. 40, 6217-6243. https://doi.org/ 10.1016/S0020-7683(03)00414-1.

Drozdov, A.D., Klitkou, R., Christiansen, J. de C., 2013. Cyclic viscoplasticity of semicrystalline polymers with finite deformations. Mech. Mater. 56, 53-64. https://doi.org/10.1016/j.mechmat.2012.09.005.

Dusunceli, N., Colak, O.U., 2008. Modelling effects of degree of crystallinity on mechanical behavior of semicrystalline polymers. Int. J. Plast. 24, 1224-1242. https://doi.org/10.1016/j.ijplas.2007.09.003.

Dusunceli, N., Colak, O.U., 2006. High density polyethylene (HDPE): experiments and modeling. Mech. Time-Dependent Mater. 10, 331-345. https://doi.org/ 10.1007/s11043-007-9026-5.

Fayolle, B., Colin, X., Audouin, L., Verdu, J., 2007. Mechanism of degradation induced embrittlement in polyethylene. Polym. Degrad. Stab. 92, 231-238. https://doi. org/10.1016/j.polymdegradstab.2006.11.012.

Fayolle, B., Richaud, E., Colin, X., Verdu, J., 2008. Review: degradation-induced embrittlement in semi-crystalline polymers having their amorphous phase in rubbery state. J. Mater. Sci. 43, 6999-7012. https://doi.org/10.1007/s10853008-3005-3.

Garcia-Gonzalez, D., Zaera, R., Arias, A., 2017. A hyperelastic-thermoviscoplastic constitutive model for semi-crystalline polymers: application to PEEK under dynamic loading conditions. Int. J. Plast. 88, 27-52. https://doi.org/10.1016/j. ijplas.2016.09.011.

Gardette, M., Perthue, A., Gardette, J.-L., Janecska, T., Földes, E., Pukánszky, B., Therias, S., 2013. Photo- and thermal-oxidation of polyethylene: comparison of mechanisms and influence of unsaturation content. Polym. Degrad. Stab. 98, 2383-2390. https://doi.org/10.1016/J.POLYMDEGRADSTAB.2013.07.017.

Gehring, F., Bouvard, J.-L., Billon, N., 2016. Modeling of time dependent mechanical behavior of polymers: comparison between amorphous and semicrystalline polyethylene terephthalate. J. Appl. Polym. Sci. 133, 1.

Ghorbel, E., 2008. A viscoplastic constitutive model for polymeric materials. Int. J. Plast. 24, 2032-2058. https://doi.org/10.1016/j.ijplas.2008.01.003.

Grigoriadou, I., Paraskevopoulos, K.M., Chrissafis, K., Pavlidou, E., Stamkopoulos, T.G., Bikiaris, D., 2011. Effect of different nanoparticles on HDPE UV stability. Polym. Degrad. Stab. 96, 151-163. https://doi.org/10.1016/J POLYMDEGRADSTAB.2010.10.001. 
Gulmine, J.V.V., Janissek, P.R.R., Heise, H.M.M., Akcelrud, L., 2003. Degradation profile of polyethylene after artificial accelerated weathering. Polym. Degrad. Stab. 79, 385-397. https://doi.org/10.1016/S0141-3910(02)00338-5.

Hachour, K., Zaïri, F., Naït-Abdelaziz, M., Gloaguen, J.M., Aberkane, M., Lefebvre, J.M., 2014. Experiments and modeling of high-crystalline polyethylene yielding under different stress states. Int. J. Plast. 54, 1-18. https://doi.org/10.1016/j. ijplas.2013.06.004

Han, X., Pan, J., 2009. A model for simultaneous crystallisation and biodegradation of biodegradable polymers. Biomaterials 30,423-430. https://doi.org/10.1016/j. biomaterials.2008.10.001.

Haward, R.N., Thackray, G., 1968. The Use of a Mathematical Model to Describe Isothermal Stress-Strain Curves in Glassy Thermoplastics. Proc. R. Soc. London. Ser. A, Math. Phys. Sci. VO - 302453.

Hsu, Y.-C., Weir, M.P., Truss, R.W., Garvey, C.J., Nicholson, T.M., Halley, P.J., 2012. A fundamental study on photo-oxidative degradation of linear low density polyethylene films at embrittlement. Polymer (Guildf). 53, 2385-2393. https://doi.org/10.1016/j.polymer.2012.03.044.

Hsueh, H.-C., Kim, J.H., Orski, S., Fairbrother, A., Jacobs, D., Perry, L., Hunston, D. White, C., Sung, L., 2020. Micro and macroscopic mechanical behaviors of highdensity polyethylene under UV radiation and temperature, Polym. Degrad. Stab. 174, Article no. 109098.

Huang, C.-C., Wei, M.-K., Lee, S., 2011. Transient and steady-state nanoindentation creep of polymeric materials. Int. J. Plast. 27, 1093-1102. https://doi.org 10.1016/j.ijplas.2010.11.005.

Johlitz, M., Diercks, N., Lion, A., 2014. Thermo-oxidative ageing of elastomers: a modelling approach based on a finite strain theory. Int. J. Plast. 63, 138-151. https://doi.org/10.1016/j.ijplas.2014.01.012.

Khan, A., Zhang, H., 2001. Finite deformation of a polymer: experiments and modeling. Int. J. Plast. 17, 1167-1188. https://doi.org/10.1016/S0749-6419(00) 00073-5.

Khan, F., Yeakle, C., 2011. Experimental investigation and modeling of nonmonotonic creep behavior in polymers. Int. J. Plast. 27, 512-521. https://doi. org/10.1016/j.ijplas.2010.06.007.

Krairi, A., Doghri, I., 2014. A thermodynamically-based constitutive model for thermoplastic polymers coupling viscoelasticity, viscoplasticity and ductile damage. Int. J. Plast. 60, 163-181. https://doi.org/10.1016/j.ijplas.2014.04.010.

Krempl, E., Khan, F., 2003. Rate (time)-dependent deformation behavior: an overview of some properties of metals and solid polymers. Int. J. Plast. 19, 1069-1095. https://doi.org/10.1016/S0749-6419(03)00002-0.

Lee, B.J., 1993. Micromechanical modeling of large plastic deformation and texture evolution in semi-crystalline polymers. J. Mech. Phys. Solids 41, 1651-1687. https://doi.org/10.1016/0022-5096(93)90018-B.

Lee, E.H., 1969. Elastic-plastic deformation at finite strains. J. Appl. Mech. 36, 1-6.

Lin, L., Argon, A.S., 1994. STRUCTURE AND PLASTIC-DEFORMATION OF POLYETHYLENE. J. Mater. Sci.

Liu, M., Horrocks, A.R., Hall, M.E., 1995. Correlation of physicochemical changes in UV-exposed low density polyethylene films containing various UV stabilisers. Polym. Degrad. Stab. 49, 151-161. https://doi.org/10.1016/0141-3910(95) 00036-L.

Makki, M., Ayoub, G., Abdul-Hameed, H., Zaïri, F., Mansoor, B., Naït-Abdelaziz, M. Ouederni, M. 2017. Mullins effect in polyethylene and its dependency on crystal content: a network alteration model. J. Mech. Behav. Biomed. Mater. 75 https://doi.org/10.1016/j.jmbbm.2017.04.022.

Makradi, A., Ahzi, S., Gregory, R.V., Edie, D.D., 2005. A two-phase self-consistent model for the deformation and phase transformation behavior of polymers above the glass transition temperature: application to PET. Int. J. Plast. 21, 741 758. https://doi.org/10.1016/j.ijplas.2004.04.012.

Maurel-Pantel, A., Baquet, E., Bikard, J., Bouvard, J.L., Billon, N., 2015. A thermomechanical large deformation constitutive model for polymers based on material network description: application to a semi-crystalline polyamide 66 . Int. J. Plast. 67, 102-126. https://doi.org/10.1016/j.ijplas.2014.10.004.

Miyagawa, E., Tokumitsu, K., Tanaka, A., Nitta, K. Hei, 2007. Mechanical property and molecular weight distribution changes with photo- and chemicaldegradation on LDPE films. Polym. Degrad. Stab. 92, 1948-1956. https://doi org/10.1016/j.polymdegradstab.2007.05.019.

Nait Abdelaziz, M., Ayoub, G., Colin, X., Benhassine, M., Mouwakeh, M., 2019. New developments in fracture of rubbers: predictive tools and influence of thermal aging. Int. J. Solids Struct. 165, 127-136. https://doi.org/10.1016/J. IJSOLSTR.2019.02.001.

Nguyen, V.-D., Lani, F., Pardoen, T., Morelle, X.P., Noels, L., 2016. A large strain hyperelastic viscoelastic-viscoplastic-damage constitutive model based on a multi-mechanism non-local damage continuum for amorphous glassy polymers. Int. J. Solids Struct. https://doi.org/http://dx.doi.org/10.1016/j. ijsolstr.2016.06.008.

Peacock, A.J., 2000. Handbook of polyethylene : structures, properties, and applications. Andrew J. Peacock., Plastics engineering: 57. New York : Marce Dekker, [2000].

Qi, Z., Hu, N., Li, G., Zeng, D., Su, X., 2019. Constitutive modeling for the elasticviscoplastic behavior of high density polyethylene under cyclic loading. Int. J. Plast. 113, 125-144. https://doi.org/10.1016/j.ijplas.2018.09.010.

Rabek, J.F., 1995. Photochemical aspects of degradation of polymers. In: Polymer Photodegradation. Springer, Netherlands, Dordrecht, pp. 24-66. https://doi.org/ 10.1007/978-94-011-1274-1_2.

Regrain, C., Laiarinandrasana, L., Toillon, S., Saï, K., 2009. Multi-mechanism models for semi-crystalline polymer: constitutive relations and finite elemen implementation. Int. J. Plast. 25, 1253-1279. https://doi.org/10.1016/j. ijplas.2008.09.010.

Richeton, J., Ahzi, S., Vecchio, K.S., Jiang, F.C., Adharapurapu, R.R., 2006. Influence of temperature and strain rate on the mechanical behavior of three amorphous polymers: characterization and modeling of the compressive yield stress. Int. J. Solids Struct. 43, 2318-2335. https://doi.org/10.1016/j.ijsolstr.2005.06.040.

Rodriguez, A.K., Mansoor, B., Ayoub, G., Colin, X., Benzerga, A.A., 2020. Effect of UVaging on the mechanical and fracture behavior of low density polyethylene. Polym. Degrad. Stab. 109185. https://doi.org/10.1016/J POLYMDEGRADSTAB.2020.109185.

Rolón-Garrido, V.H., Kruse, M., Wagner, M.H., 2015. Size exclusion chromatography of photo-oxidated LDPE by triple detection and its relation to rheological behavior. Polym. Degrad. Stab. 111, 46-54. https://doi.org/10.1016/J. POLYMDEGRADSTAB.2014.10.022.

Salivon, T., Colin, X., Comte, R., 2015. Degradation of XLPE and PVC cable insulators. In: 2015 IEEE Conference on Electrical Insulation and Dielectric Phenomena (CEIDP), pp. 656-659. https://doi.org/10.1109/CEIDP.2015.7352022.

Sebaa, M., Servens, C., Pouyet, J., 1993. Natural and artificial weathering of lowdensity polyethylene (Ldpe) - calorimetric analysis. J. Appl. Polym. Sci. 47, 1897-1903. https://doi.org/10.1002/app.1993.070471101.

Selles, N., Saintier, N., Laiarinandrasana, L., 2016. Voiding mechanisms in semicrystalline polyamide 6 during creep tests assessed by damage based constitutive relationships and finite elements calculations. Int. J. Plast. 86, 112-127. https://doi.org/10.1016/j.ijplas.2016.08.004.

Soares, J.S., Moore, J.E., Rajagopal, K.R., 2008. Constitutive framework for biodegradable polymers with applications to biodegradable stents. ASAIO J. 54, 295-301. https://doi.org/10.1097/MAT.0b013e31816ba55a.

Soares, J.S., Rajagopal, K.R., Moore, J.E., 2010. Deformation-induced hydrolysis of a degradable polymeric cylindrical annulus. Biomech. Model. Mechanobiol. 9, 177-186. https://doi.org/10.1007/s10237-009-0168-z.

Tavares, A.C., Gulmine, J.V., Lepienski, C.M., Akcelrud, L., 2003. The effect of accelerated aging on the surface mechanical properties of polyethylene. Polym. Degrad. Stab. 81, 367-373. https://doi.org/10.1016/S0141-3910(03)00108-3.

Tireau, J., Van Schoors, L., Benzarti, K., Colin, X., 2009. Environmental ageing of carbon black-filled polyethylene sheaths employed in civil engineering. J. Nanostruct. Polym. Nanocompos. 5, 94-100.

van Dommelen, J.A.W., Parks, D.M., Boyce, M.C., Brekelmans, W.A.M., Baaijens, F.P.T., 2003. Micromechanical modeling of the elasto-viscoplastic behavior of semicrystalline polymers. J. Mech. Phys. Solids 51, 519-541. https://doi.org/10.1016/ S0022-5096(02)00063-7.

Vieira, A.C., Guedes, R.M., Tita, V., 2014. Constitutive modeling of biodegradable polymers: Hydrolytic degradation and time-dependent behavior. Int. J. Solids Struct. 51, 1164-1174. https://doi.org/10.1016/j.ijsolstr.2013.12.010.

Vieira, A.C., Marques, A.T., Guedes, R.M., Tita, V., 2011. Material model proposal for biodegradable materials. Procedia Eng., 1597-1602 https://doi.org/10.1016/j. proeng.2011.04.267.

Volokh, K., 2016. Mechanics of soft materials. Mech. Soft Mater. https://doi.org/ 10.1007/978- 981-10-1599-1.

Volokh, K.Y., 2017. Loss of ellipticity in elasticity with energy limiters. Eur. J. Mech. A/Solids 63, 36-42. https://doi.org/10.1016/j.euromechsol.2016.10.003.

Volokh, K.Y., 2010. On modeling failure of rubber-like materials. Mech. Res. Commun. 37, 6 84-6 89. https://doi.org/10.1016/j.mechrescom.2010.10.006

Volokh, K.Y., 2007. Hyperelasticity with softening for modeling materials failure. J. Mech. Phys. Solids 55, 2237-2264. https://doi.org/10.1016/j.jmps.2007.02.012.

Wang, Y., Han, X., Pan, J., Sinka, C., 2010. An entropy spring model for the Young's modulus change of biodegradable polymers during biodegradation. J. Mech. Behav. Biomed. Mater. 3, 14-21. https://doi.org/10.1016/j.jmbbm.2009.02.003.

Wang, Y., Pan, J., Han, X., Sinka, C., Ding, L., 2008. A phenomenological model for the degradation of biodegradable polymers. Biomaterials 29, 3393-3401. https:// doi.org/10.1016/j.biomaterials.2008.04.042.

Ward, I.M., Sweeney, J., 2005. An Introduction to the Mechanical Properties of Solid Polymers. J. Wiley \& Sons.

Wu, P.D., van der Giessen, E., 1995. On neck propagation in amorphous glassy polymers under plane strain tension. Int. J. Plast. 11, 211-235. https://doi.org/ 10.1016/0749-6419(94)00043-3.

Wu, P.D., Van der Giessen, E., 1996. Computational aspects of localized deformations in amorphous glassy polymers. Eur. J. Mech. A Solids 15 (5), 799-823.

Zaïri, F., Naït-Abdelaziz, M., Gloaguen, J.M., Lefebvre, J.M., 2011. A physically-based constitutive model for anisotropic damage in rubber-toughened glassy polymers during finite deformation. Int. J. Plast. 27, 25-51. https://doi.org/ 10.1016/j.ijplas.2010.03.007.

Zaïri, F., Naït-Abdelaziz, M., Gloaguen, J.M., Lefebvre, J.M., 2008. Modelling of the elasto-viscoplastic damage behaviour of glassy polymers. Int. J. Plast. 24, 945965. https://doi.org/10.1016/j.ijplas.2007.08.001.

Zaïri, F., Naït-Abdelaziz, M., Woznica, K., Gloaguen, J.-M., 2005a. Constitutive equations for the viscoplastic-damage behaviour of a rubber-modified polymer. Eur. J. Mech. - A/Solids 24, 169-182. https://doi.org/10.1016/j. euromechsol.2004.11.003.

Zaïri, F., Woznica, K., Naït-Abdelaziz, M., 2005b. Phenomenological nonlinear modelling of glassy polymers. Comptes Rendus Mécanique 333, 359-364. https://doi.org/10.1016/j.crme.2005.02.003.

Zhang, C., Moore, I.D., 1997. Nonlinear mechanical response of high density polyethylene. Part II: Uniaxial constitutive modeling. Polym. Eng. Sci. 37, 414420. 
Zhao, B., Awartani, O., O'Connor, B., Zikry, M.A., 2016. Microstructural behavior and failure mechanisms of organic semicrystalline thin film blends. J. Polym. Sci. Part B Polym. Phys. 54, 896-907. https://doi.org/10.1002/polb.23991.
Zhao, B., Zikry, M.A.A., 2017. Oxidation-induced failure in semi-crystalline organic thin films. Int. J. Solids Struct. 109, 72-83. https://doi.org/10.1016/j. ijsolstr.2017.01.008. 